\title{
Progressive immediate loading of a perforated maxillary sinus dental implant: a case report
}

This article was published in the following Dove Press journal:

Clinical, Cosmetic and Investigational Dentistry

29 January 2015

Number of times this article has been viewed

\section{Mohammed Jasim \\ Al-Juboori}

Department of Oral Surgery, MAHSA University, Kuala Lumpur, Malaysia

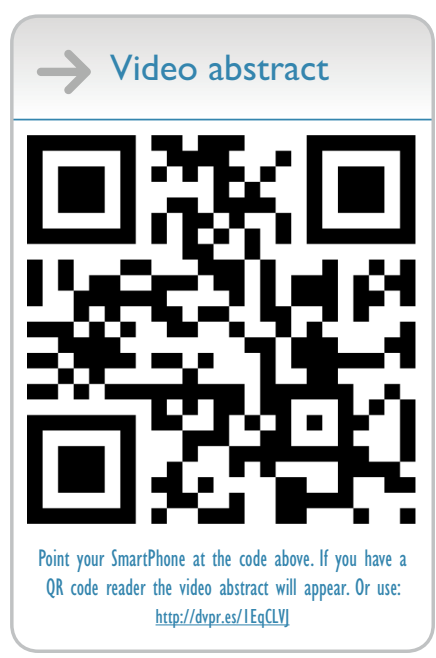

Correspondence: Mohammed Jasim Al-Juboori

Department of Oral Surgery, MAHSA

University, Dental Faculty, Block E,

Fourth Floor, Pusat Bandar Damansara,

Damansara Heights, 50490,

Kuala Lumpur, Malaysia

Email doctor_mohamed_2006@yahoo.

com
Abstract: The displacement of a dental implant into the maxillary sinus may lead to implant failure due to exposure of the apical third or the tip of the implant beyond the bone, resulting in soft tissue growth. This case report discusses dental implant placement in the upper first molar area with maxillary sinus involvement of approximately $2 \mathrm{~mm}$. A new technique for progressive implant loading was used, involving immediately loaded implants with maxillary sinus perforation and low primary stability. Follow-up was performed with resonance frequency analysis and compared with an implant placed adjacent in the upper second premolar area using a conventional delayed loading protocol. Implants with maxillary sinus involvement showed increasing stability during the healing period. We found that progressive implant loading may be a safe technique for the placement of immediately loaded implants with maxillary sinus involvement.

Keywords: progressive implant loading, resonance frequency analysis, implant stability, provisional crown, bone density, maxillary sinus

\section{Introduction}

According to Lekholm and Zarb, ${ }^{1}$ the bone density of the posterior maxilla is classified as type 4 bone, which means that a thin layer of cortical bone surrounds low-density trabecular bone. Implants placed in soft bone or D4 bone require a longer healing period for better bone remodeling and maturation. A poor bone density does not provide support for the implant during the healing and loading stages. ${ }^{2-4}$ Higher implant failure rates have consistently been found in areas of poor bone quality, such as the posterior segment of the maxilla..$^{5,6}$

There are several special considerations that should be taken into account when implants are placed in the posterior maxillary area, including drilling an undersized preparation to obtain primary stability, using a modified (roughened) implant surface, using a wide diameter and aggressively designed implant, and using a submerged technique to avoid implant loading stress. All of these measures result in an increased implant surface area that enhances bone implant contact and implant stability. ${ }^{3,7,8}$ The progressive implant loading technique was developed by Misch $^{9}$ for implants placed in areas with poor bone density. This technique allows bone to mature during the loading period without overloading the implant and resulting in bone loss or implant failure. ${ }^{10}$ Ban et $\mathrm{al}^{11}$ conducted a study comparing the differences between progressive, immediate, and delayed loading of implants. The result was a significant increase in bone implant contact and a decrease in vertical bone loss in the progressive loading group. Maxillary sinus floor perforation during implant placement resulting from overestimation of the bone height has many consequences depending on the severity of injury. 
Primarily, sinus involvement during implant placement may prevent osseointegration of the apical part of the fixture. ${ }^{12}$ Additionally, soft tissue from the floor of the sinus may grow on the apex of the implant instead of bone, affecting the final prognosis. ${ }^{12}$ Sinus infection and sinusitis may also occur if bacteria proliferate on the apex of the implant surface, affecting the process of bone remodeling. ${ }^{13-15}$ It is also possible for no adverse consequences to occur and for new bone to form around and above the apex of the implant. ${ }^{12}$ Our case report consists of two sections: the first describes maxillary sinus perforations and their effect on implant prognosis and survival, and the second discusses the novel technique of immediate progressive implant loading.

\section{Case report}

The patient was a 52-year-old woman with no history of systemic disease or parafunctional occlusion. The patient presented to our facility with a main request to replace her missing maxillary left second premolar and first molar with implants. An orthopantomogram was taken (Figure 1), and after clinical and radiographic examination, a taper implant with a $4.0 \mathrm{~mm}$ width and a $10 \mathrm{~mm}$ length was selected for replacement of both teeth. Using local anesthesia, a crestal incision was performed without vertical extension. The bone was then exposed and prepared according to the manufacturer's recommendations. During preparation of the first molar socket, the resistance to drilling decreased, indicating sinus floor penetration. Because the bone density was poor, the final drill was inserted halfway, and two implants with a diameter of $4.0 \mathrm{~mm}$ and length of $10 \mathrm{~mm}$ were placed, replacing the first molar and second premolar. The implant design was a tapered, modified surface (sand-blasted, large grit, acid-etched [SLA]) that was threaded to the top (Superline ${ }^{\mathrm{TM}}$, Dentium, Cypress, CA, USA) to achieve better

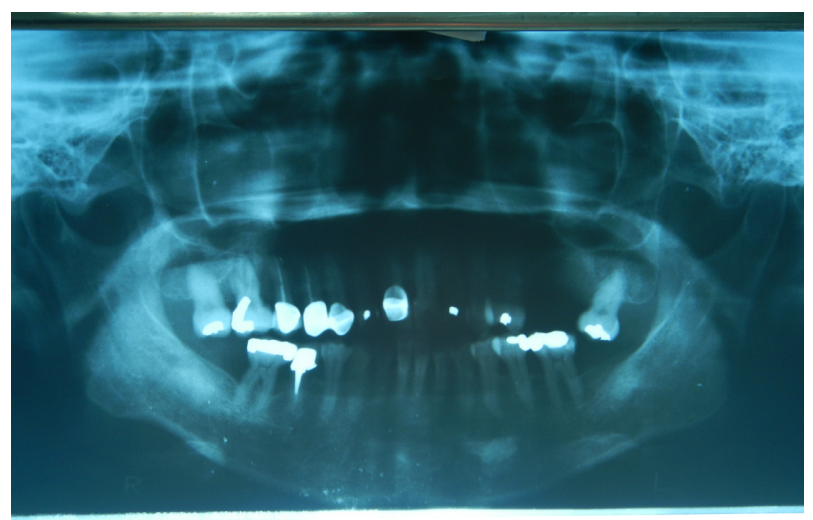

Figure I Orthopantamograph taken preoperatively showing maxillary sinus pneumatization in the extracted site 25 and 26 area. implant stability and increase the implant surface area in contact with the surrounding bone. Implants were placed approximately $1 \mathrm{~mm}$ subcrestally, and resonance frequency analysis (RFA) measurements were taken for both implants (Table 1). The reading for the second premolar implant was 73 ISQ (implant stability quotient) in all four directions, and for the first molar implant, the reading was 69 ISQ in all directions except for the buccolingual direction, which was 64 ISQ. A cover screw was placed on the second premolar implant and covered with gingival tissue to obtain primary closure and allow healing using the submerged technique. The first molar implant was immediately loaded with a temporary plastic abutment, and a crown was fabricated from a light-cured composite resin material (Figure 2). At this stage, the crown was out of occlusion, with a narrow occlusal table and no interproximal contact (Figures 3 and 4). The tissue flap was adapted to the temporary crown, and the gingiva was sutured around it (Figure 5). A periapical radiograph was taken postoperatively for both implants and was considered a basic radiograph (Figure 6). The radiograph shows the implant in the molar area penetrating the maxillary sinus approximately $2-3 \mathrm{~mm}$.

Table I Immediate progressive implant loading RFA measurement versus delay implant loading RFA measurement over a period of 3 months

\begin{tabular}{lll}
\hline RFA direction & \multicolumn{2}{l}{ At implant placement } \\
\cline { 2 - 3 } & First molar & Second premolar \\
\hline Mesiodistal & 69 & 73 \\
Lingobuccal & 69 & 73 \\
Buccolingual & 64 & 73 \\
Distomesial & 69 & 73 \\
Average & 67 & 73 \\
After one month & & \\
Mesiodistal & $73 \uparrow$ & - \\
Lingobuccal & $70 \uparrow$ & - \\
Buccolingual & $70 \uparrow$ & - \\
Distomesial & $73 \uparrow$ & - \\
Average & 71 & \\
After 2 months & & $76 \uparrow$ \\
Mesiodistal & $75 \uparrow$ & $66 \downarrow$ \\
Lingobuccal & $70 \leftrightarrow$ & $66 \downarrow$ \\
Buccolingual & $70 \leftrightarrow$ & $76 \uparrow$ \\
Distomesial & $75 \uparrow$ & 71 \\
Average & 72 & $79 \uparrow$ \\
After 3 months & & $70 \uparrow$ \\
Mesiodistal & $75 \leftrightarrow$ & $70 \uparrow$ \\
Lingobuccal & $71 \uparrow$ & $75 \downarrow$ \\
Buccolingual & $71 \uparrow$ & 73 \\
Distomesial & $75 \leftrightarrow$ & \\
Average & 74 & \\
\hline Abreviaton: & & \\
\hline
\end{tabular}

Abbreviation: RFA, resonance frequency analysis. 


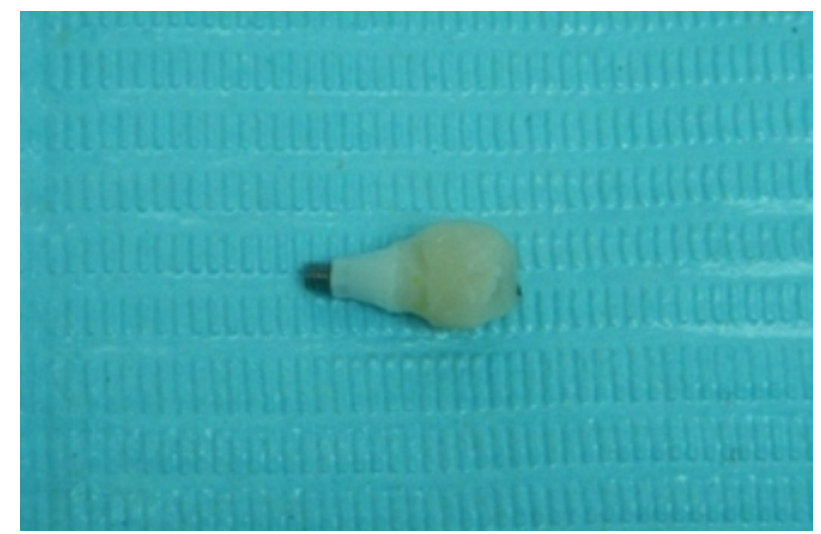

Figure 2 Temporary abutment with crown fabrication from composite filling for easy adjustment and modification. Fabrication, contouring, and polishing were performed outside the patient's mouth.

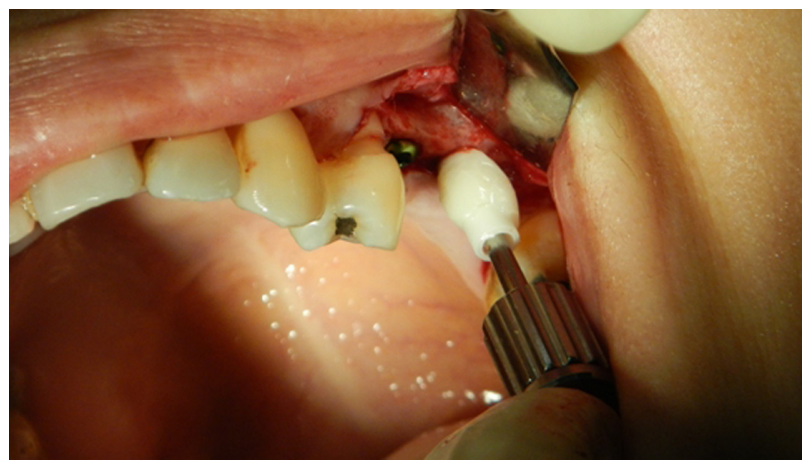

Figure 3 Temporary abutment and crown installed into the 26-position implant and torque before flap closure. Cover screw used for the 25 -position implant, which was placed with the submerged technique and left to heal for 2 months before re-entry.

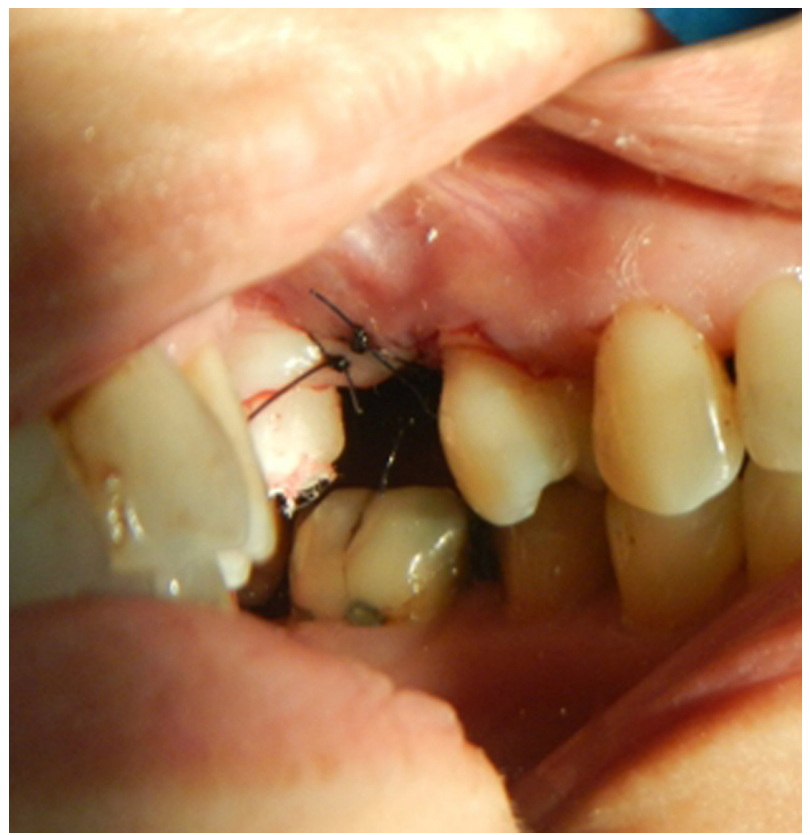

Figure 4 Occlusion was checked before releasing the patient. The crown was left out of occlusion to prevent any occlusal loading during the early healing period.

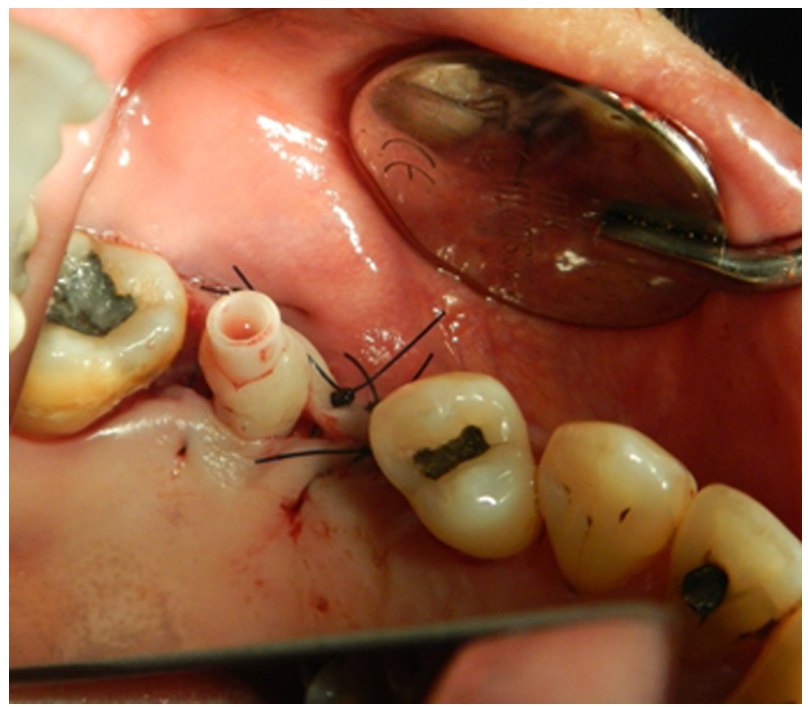

Figure 5 Occlusal view of the temporary abutment and crown issued on the day of surgery (implant placement); small occlusal table with no adjacent tooth contact. The flap was adapted around the crown (simultaneously covering the 25-position implant) and sutured with nylon sutures.

Postoperative instructions were given, and after 10 days the patient returned for suture removal and follow-up. Both implant sites healed uneventfully, and the sutures were removed. No signs or symptoms of maxillary sinus infection or inflammation were reported by the patient. One month after implant placement, the temporary abutment and crown were removed. The RFA measurements taken at that time were 73 ISQ in the mesiodistal and distomesial directions and 70 ISQ in the buccolingual and lingobuccal directions. The crown was modified (Figure 7) by increasing the width of the occlusal table and obtaining distal contact with the adjacent tooth (upper right second molar). At this stage, the crown remained out of occlusion (no increase in crown height).

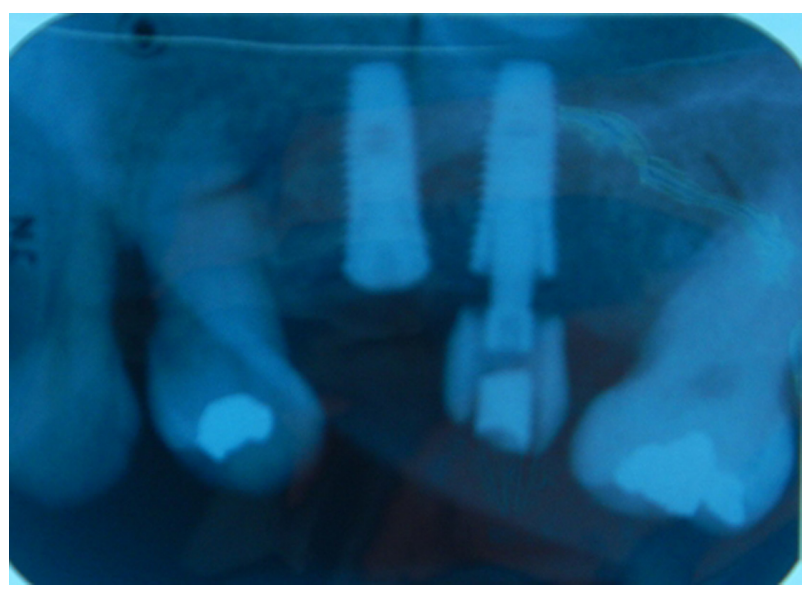

Figure 6 An immediate postoperative periapical radiograph showing the 16-position implant penetrating the maxillary sinus by a few millimeters. 


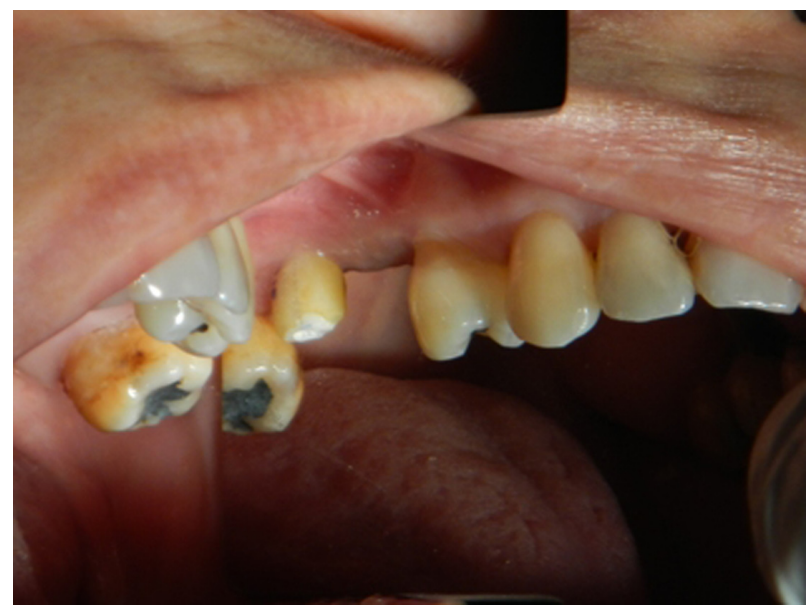

Figure 7 Second stage of temporary crown modification I month after implant placement. The crown now has contact with adjacent tooth 27 , as it has a wider diameter but is still out of occlusion.

The crown was polished and again screwed into the fixture. Again, the patient was examined for any signs or symptoms of maxillary sinus infection, and none were found.

Two months after implant placement, the patient returned for the third stage of crown modification. The temporary abutment and crown were removed, and the RFA measurements taken at this time were 75 ISQ in the mesiodistal and distomesial directions and 70 ISQ in the buccolingual and lingobuccal directions. The crown was modified by increasing the vertical height and obtaining occlusal contact with the opposing tooth in the axial direction only (Figure 8). Occlusal contacts during excursive movements were removed, and only central contact remained. During the same appointment, the second premolar implant was uncovered, and the RFA measurements taken were 76 ISQ

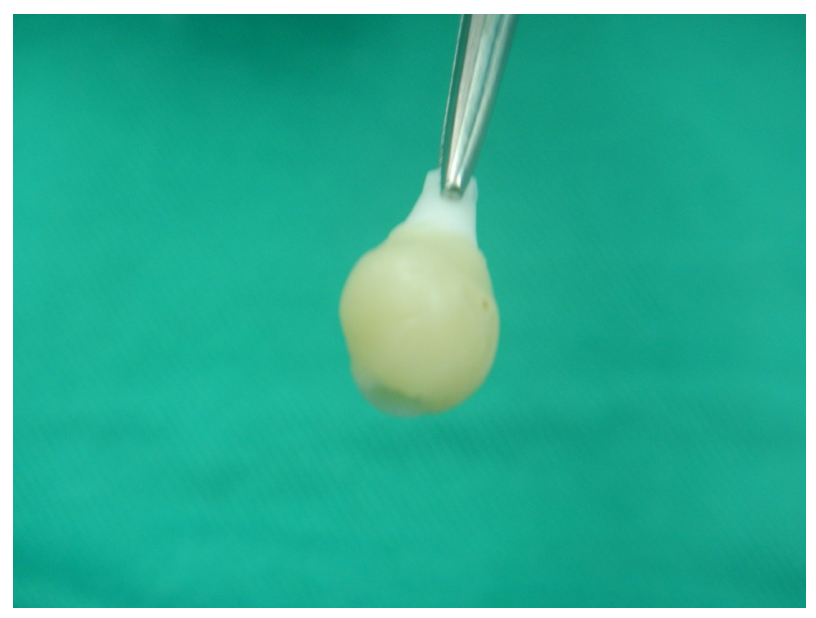

Figure 8 Third stage of temporary crown modification. After 2 months of implant placement, an increase in the diameter of the crown was done. The crown was contoured to resemble the natural tooth anatomy. in the mesiodistal and distomesial directions and 66 ISQ in the buccolingual and lingobuccal directions. A healing abutment was placed and left for 1 month to allow healing of the soft tissue (Figure 9).

Three months after implant placement (Figure 10), the RFA measurement for the first molar was 75 ISQ in the mesiodistal, lingobuccal, and distomesial directions and 71 ISQ in the buccolingual direction. For the second premolar, the RFA values were 75 ISQ in the mesiodistal direction, 79 ISQ in the distomesial direction, and 70 ISQ in the buccolingual and lingobuccal directions. Impressions were taken at this appointment using a closed-tray technique and hex coping. Jaw relationships and bite registration were obtained using a wax bite rim and O-bite. Titanium hex abutments were placed using $30 \mathrm{Ncm}$ of force for both implants, and provisional crowns were cemented with temporary cement (Figure 11). Occlusion was checked and adjusted, leaving only centric occlusal contacts and removing all contacts found during excursive movements (Figure 11). A periapical radiograph after abutment installation was taken (Figure 12). Final crowns will be placed 6 months after cementation of provisional crowns.

\section{Discussion}

Maxillary sinus involvement during implant placement may lead to decreased contact of the implant with bone and prevent osseointegration of the apical portion of the fixture. ${ }^{12}$ Soft tissue from the floor of the sinus may grow instead of bone, which affects the prognosis. ${ }^{12}$ Additionally, sinus infection and sinusitis may occur ${ }^{13-15}$ due to bacterial growth on the apex of the implant surface, making bone formation and osseointegration impossible. Some authors recommend engaging the apex of the implant with the sinus floor to obtain increased implant stability because the sinus

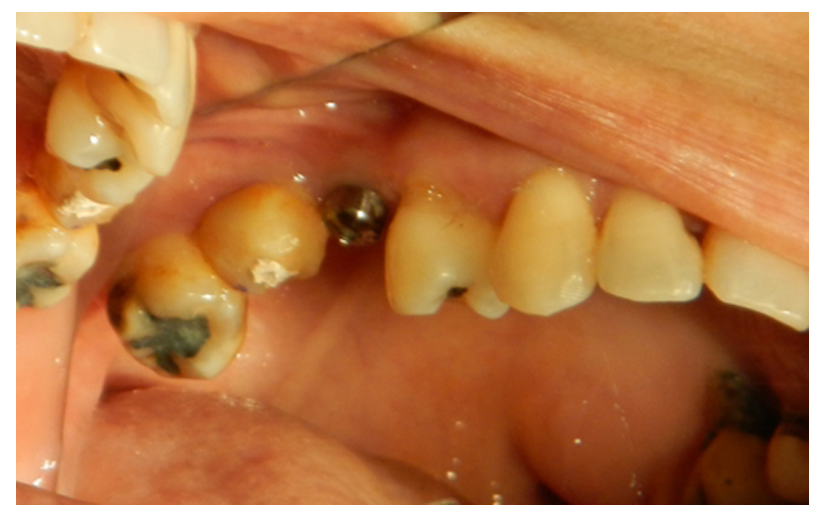

Figure 9 Temporary crown increased in size, and implant with light center occlusion. The implant in position 25 is now exposed, and the healing abutment is installed. 


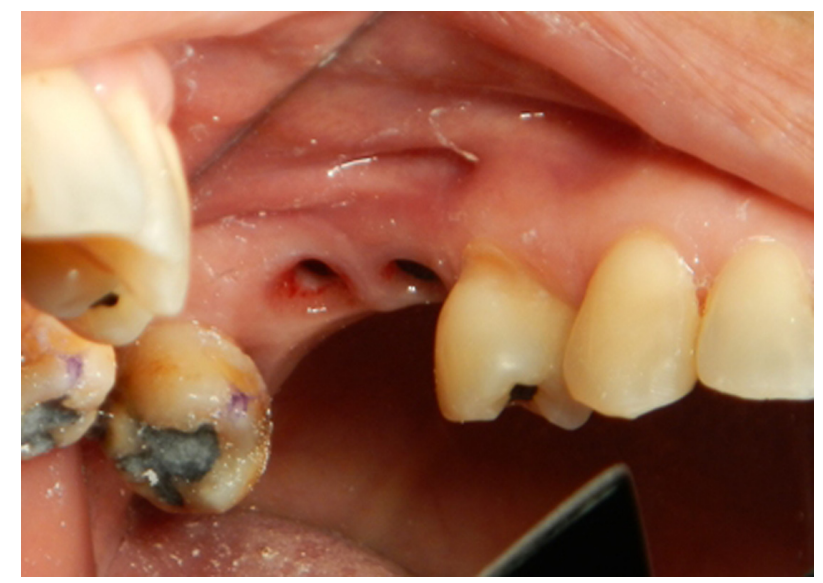

Figure 10 Differences are seen in the gingival contour around temporary crown 26 and healing abutment in the 25 -position implant. The emergence profile is achieved, and interdental papillae are growing around the temporary abutment.

floor is composed of dense cortical bone. ${ }^{16,17}$ Zhong et al ${ }^{12}$ conducted histological studies on canines, concluding that penetration of dental implants into the maxillary sinus with membrane perforation does not necessarily compromise implant osseointegration and sinus health during the 5-month observation period. ${ }^{12}$ The same researchers concluded that if the implant apex protruded $2 \mathrm{~mm}$ or less into the sinus, it was possible for healthy maxillary bone to regenerate over the apex of the implant. However, when the perforation was more than $3 \mathrm{~mm}$, the soft tissue formed a cuff around the implant. ${ }^{12}$ This effect may be due to elasticity of the Schneiderian membrane, which can stretch approximately $2 \mathrm{~mm}$ before perforating.

The second part of this case report describes a progressive implant loading technique that has been modified by the author. Progressive implant loading was developed by Misch ${ }^{9}$ and is recommended for implants that have been placed in soft bone or grafted sites. After the osseointegration period, the implant is exposed and progressively loaded to prevent overloading while simultaneously increasing bone density. Our technique is recommended for implants placed in soft bone with immediate loading. Implant loading within physiological limits can enhance bone formation and increase bone density. This case report illustrates how progressive loading with staging increases the width of the occlusal table and how the height of the crown can increase implant stability, especially if performed within the first 4 weeks. Many studies have shown that there is decreased implant stability during the first 4 weeks of the healing period due to active bone remodeling and new immature bone formation. ${ }^{18-20}$ When we compared immediate progressive loading of implants with low primary stability to submerged healing of implants with

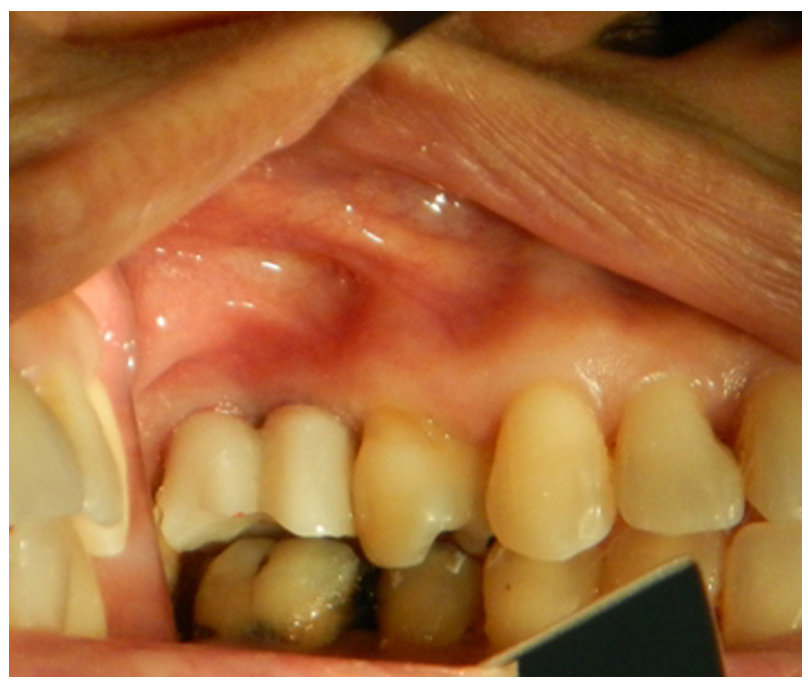

Figure I I Acrylic provisional crown received from the laboratory and issued with a customized abutment; only light and centric occlusion is allowed on the provisional crowns.

higher primary stability, RFA showed an increased reading of 72 ISQ for the loaded implant, while a decrease in implant stability was found for the submerged implant with a reading of 71 ISQ after a 2-month healing period. This provides additional evidence that progressive loading of implants can stimulate bone formation and increase bone density compared with placement of implants using the conventional technique of delayed loading. Ban et $\mathrm{al}^{13}$ reported that progressive implant loading can accelerate the mineralization process during the first 28 days of the healing period. Placing an implant into soft bone and immediately loading it is considered a risky procedure ${ }^{10}$ because soft bone does not support implants well; consequently, protective measures should be taken. ${ }^{2,3,13,19,20}$

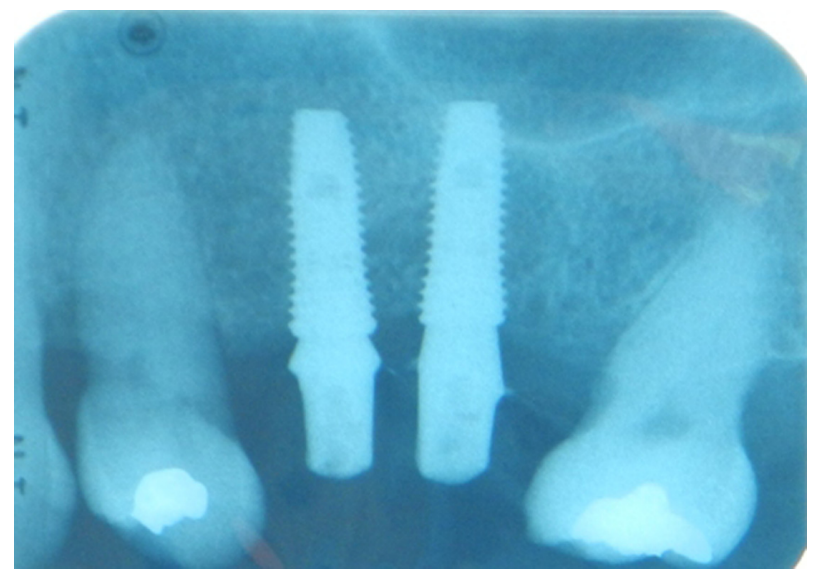

Figure 12 Periapical radiograph after abutment installation does not reveal any bone resorption or radiolucencies around either implant, with a stable bone crest around the 26-position implant despite many abutment disconnections. There are no complications in the apical penetrating part of the 26-position implant. 
Protective measures for achieving primary stability ${ }^{10}$ include choosing a wider diameter implant to increase the surface area and bone implant contact. ${ }^{6,11}$ Aggressive implant designs, which entail deep threads that extend to the top, allow the implant to engage additional bone during placement due to an increased surface area. ${ }^{21}$ Special considerations for socket preparation include inserting the last drill halfway or occasionally skipping the last drill so that the implant is placed in an undersized socket. ${ }^{6}, 10$ Tapered implant designs allow the coronal part of the implant to engage the cortical bone of the alveolar crest. Placing implants subcrestally by approximately $1 \mathrm{~mm}$ provides additional protection to the implant and allows increased engagement of the cortical bone. ${ }^{22,23}$

Another factor related to implant stability is the surface of a treated implant. Many studies have shown that implants with an SLA surface can enhance bone formation and act as a chemotactic factor for osteogenic cells. ${ }^{24}$ SLA surfaces may enhance the quality of soft bone surrounding the implant by increasing its density. ${ }^{25,26}$ All of the above factors should be considered when implants are placed in soft bone and immediately loaded. The concept for this technique originated from the process of tooth eruption: during eruption, the tooth has a partially developed root, and when it finally erupts into occlusion with its antagonist, only three quarters of the root has been formed. ${ }^{26}$ Similarly, with this technique, we attempt to make the implant "erupt" into the oral cavity by progressively increasing the crown width and height. This process allows time for the bone to grow and mature with the increased loading stimuli, resulting in implant stability and increased bone density. In other words, the technique can be called "implant eruption".

\section{Conclusion}

Progressive implant loading can be used as a safe technique for the immediate loading of implants with maxillary sinus involvement. Progressive implant loading can enhance implant stability during the healing period. No adverse consequences were found when the maxillary sinus floor was perforated, provided that the membrane was intact and healthy and the implant protrusion into the sinus was within $2 \mathrm{~mm}$.

\section{Acknowledgment}

The author is grateful to Lee Li Chong and Monica Arrogancia for their extensive assistance with the clinical portion of this study.

\section{Disclosure}

The author reports no conflicts of interest in this work.

\section{References}

1. Lekholm U, Zarb G. Patient selection and preparation. In: Bffmemark P-I, Zarb G, Albrektsson T, editors. Tissue-Integrated Prosthesis: Osseointegration in Clinical Dentistry. Chicago, IL, USA: Quintessence; 1985.

2. Bischof M, Nedir R, Szmukler-Moncler S, Bernard JP, Samson J. Implant stability measurement of delayed and immediately loaded implants during healing. Clin Oral Implants Res. 2004;15: 529-539.

3. Mesa F, Munoz R, Noguerol B, de Dios Luna J, Galindo P, O’Valle, F. Multivariate study of factors influencing primary dental implant stability. Clin Oral Implants Res. 2008;19:196-200.

4. Lorenzoni M, Pertl C, Zhang K, Wegscheider WA. Inpatient comparison of immediately loaded and nonleaded implants within 6 months. Clin Oral Implants Res. 2003;14:273-279.

5. Jaffin RA, Berman CL. The excessive loss of Branemark fixtures in type IV bone: a 5-year analysis. J Periodontol. 1991;62:2-4.

6. Fugazzotto PA, Wheeler SL, Lindsay JA. Success and failure rates of cylinder implants in type IV bone. J Periodontol. 1993;64:1085-1087.

7. Fanuscu MI, Chang TL, Akca K. Effect of surgical techniques on primary implant stability and peri-implant bone. J Oral Maxillofac Surg. 2007;65:2487-2491.

8. Glauser R, Sennerby L, Meredith N, et al. Resonance frequency analysis of implants subjected to immediate or early functional occlusal loading. Successful vs failing implants. Clin Oral Implants Res. 2004;15: 428-434.

9. Misch CE. Density of bone: effect on surgical approach and healing. In: Misch CE, editor. Contemporary Implant Dentistry. 3rd ed. St Louis, MO, USA: Mosby-Year Book; 2008:668-683.

10. Lorenzoni M, Pertl C, Zhang K, Wimmer G, Wegscheider WA. Immediate loading of single-tooth implants in the anterior maxilla. Preliminary results after one year. Clin Oral Implants Res. 2003;14: 180-187.

11. Ban Y, Gong P, Wang SA, et al. Histological and radiological evaluation of progressive loading on implant placed into extraction socket. Key Eng Mater. 2007;332:1413-1416.

12. Zhong W, Chen B, Liang X, Ma G. Experimental study on penetration of dental implants into the maxillary sinus in different depths. $J$ Appl Oral Sci. 2013;21:560-566.

13. Cordioli G, Mazzocco C, Schepers E, Brugnolo E, Majzoub Z. Maxillary sinus floor augmentation using bioactive glass granules and autogenous bone with simultaneous implant placement. Clinical and histological findings. Clin Oral Implants Res. 2001;12:270-278.

14. Van den Bergj JP, ten Ruggenkate CM, Disch FJ, Tuinzing DB. Anatomical aspects of sinus floor elevations. Clin Oral Implants Res. 2000;11:256-265.

15. Raghoebar GM, Weissenbruch R, Vissink A. Rhino-sinusitis related to endosseous implants extending into the nasal cavity. A case report. Int J Oral Maxillofac Surg. 2004;33:312-314.

16. Chiapasco M, Gatti C, Rossi E, Haefliger W, Markwalder TH. Implantretained mandibular overdentures with immediate loading. A retrospective multicenter study on 226 consecutive cases. Clin Oral Implants Res. 1997;8:48-57.

17. Schnitman PA, Wohrle PS, Rubenstein JE, DaSilva JD, Wang NH. Ten-year results for Branemark implants immediately loaded with fixed prostheses at implant placement. Int J Oral Maxillofac Implants. 1997; 12:495-503.

18. Crismani AG, Bernhart T, Schwarz K, Celar AG, Bantleon HP, Watzek G. Ninety percent success in palatal implants loaded 1 week after placement: a clinical evaluation by resonance frequency analysis. Clin Oral Implants Res. 2006;17:445-450. 
19. Valderrama P, Oates TW, Jones AA, Simpson J, Schoolfield JD, Cochran DL. Evaluation of two different resonance frequency devices to detect implant stability: a clinical trial. J Periodontol. 2007;78: 262-272.

20. Huwiler MA, Pjetursson BE, Bosshardt DD, Salvi GE, Lang NP. Resonance frequency analysis in relation to jawbone characteristics and during early healing of implant installation. Clin Oral Implants Res. 2007:18:275-280.

21. Miyamoto I, Tsuboi Y, Wada E, Suwa H, Iizuka T. Influence of cortical bone thickness and implant length on implant stability at the time of surgery - clinical, prospective, biomechanical, and imaging study. Bone. 2005;37:776-780.

22. Al-Nawas B, Groetz KA, Goetz H, Duschner H, Wagner W. Comparative histomorphometry and resonance frequency analysis of implants with moderately rough surfaces in a loaded animal model. Clin Oral Implants Res. 2008;19:1-8.
23. Gapski R, Wang H-L, Mascarenhas P, Lang NP. Critical review of immediate implant loading. Clin Oral Implants Res. 2003;14:515-527.

24. Salvi GE, Gallini G, Lang NP. Early loading (2 or 6 weeks) of sandblasted and acid-etched (SLA) ITI implants in the posterior mandible. A 1-year randomized controlled clinical trial. Clin Oral Implants Res. 2004; $15: 142-149$.

25. Grassi S, Piattelli A, de Figueiredo LC, et al. Histologic evaluation of early human bone response to different implant surfaces. J Periodontol. 2006;77:1736-1743.

26. Ash MM, Nelson SJ. Development and Eruption of the Teeth. Wheeler's Dental Anatomy, Physiology and Occlusion. Philadelphia, PA, USA: WB Saunders; 2003.
Clinical, Cosmetic and Investigational Dentistry

\section{Publish your work in this journal}

Clinical, Cosmetic and Investigational Dentistry is an international, peer-reviewed, open access, online journal focusing on the latest clinical and experimental research in dentistry with specific emphasis on cosmetic interventions. Innovative developments in dental materials, techniques and devices that improve outcomes and patient satisfaction

\section{Dovepress}

and preference will be highlighted. The manuscript management system is completely online and includes a very quick and fair peerreview system, which is all easy to use. Visit http://www.dovepress. com/testimonials.php to read real quotes from published authors.

Submit your manuscript here: http://www.dovepress.com/clinical-cosmetic-and-investigational-dentistry-journal 